\title{
STUDY OF OUTCOME OF DISTAL TIBIAL FRACTURES TREATED WITH LOCKING COMPRESSION PLATES: BY BOTH OPEN REDUCTION AND MIPO TECHNIQUE
}

\author{
Ravikiran Nandirajuㄴ, D. S. Ramnath ${ }^{2}$, M. Abhinandan Reddy33, Saketh Kolla ${ }^{4}$ \\ ${ }^{1}$ Assistant Professor, Department of Orthopaedics, Osmania Medical College and Hospital, Hyderabad. \\ 2 Professor In-Charge, Department of Orthopaedics, Government Medical College, Nizamabad. \\ ${ }^{3}$ Senior Resident, Department of Orthopaedics, Osmania Medical College and Hospital, Hyderabad. \\ ${ }^{4}$ Senior Resident, Department of Orthopaedics, Osmania Medical College General Hospital, Hyderabad.
}

\section{ABSTRACT}

\section{BACKGROUND}

Tibia being the most common fractured long bone of the body; 1 . Distal metaphyseal fractures comprise 5-7\% of these injures; 2. With or without involving the articular surface. Encouraging results for open reduction and internal fixation (Plate osteosynthesis) and closed manual reduction with osteosynthesis with minimal invasive percutaneous locking plates has been noted for lower third tibial fractures. Locking compression plate provides the advantage of anatomic reduction, stable fixation, preservation of blood supply, preventing joint stiffness, less soft tissue injury.

\section{METHODS AND MATERIAL}

This study included (40) patients with distal tibia fractures between 18-65 years presenting in the Department of Orthopaedics in Osmania Medical College and Osmania General Hospital .This is prospective study. These patients are treated with locking compression plates.

\section{RESULTS}

Patients were evaluated using AOFAS7 score for hindfoot scale (100 points). Excellent - 26 (65\%), Good - 12 (30\%), Fair - 2 (5\%) comparable to other studies.

\section{CONCLUSION}

Reduction and internal fixation of distal tibial fractures using locking compression plate medially by open and MIPO technique is one of the acceptable forms of treatment for lower third tibia including the articular surface with or without communication.

\section{KEYWORDS}

Distal Tibial Fractures, ORIF, MIPO, Locking Compression Plates.

HOW TO CITE THIS ARTICLE: Nandiraju R, Ramnath DS, Reddy MA, et al. Study of outcome of distal tibial fractures treated with locking compression plates: by both open reduction and MIPO technique. J. Evolution Med. Dent. Sci. 2016;5(54):3657-3661, DOI: $10.14260 /$ jemds/2016/842

\section{INTRODUCTION}

Tibia being the most common fractured long bone of the body, 1 distal metaphyseal fractures comprise $5-7 \%$ of these injures. ${ }^{2}$ with or without involving the articular surface, also known as pilon fractures. Important variables affecting the clinical outcome of these fracture are fracture pattern and type, trauma associated to the surrounding soft tissue, modality and method of fracture treatment, and caliber of reduction of fracture and articular surface. Fracture of lower third of tibia is very common in males of 30-50 years age group and mostly due to high energy injures like road traffic injures, fall from height, or sports injuries. ${ }^{3}$

This fracture poses challenges for the orthopaedic traumatologist as it is prone to complications due to distal part of tibia is weight bearing, inherent instability, bone being subcutaneous in whole extent with minimal soft tissue cover, poor blood supply, frequently being comminuted and compound.

Financial or Other, Competing Interest: None.

Submission 09-06-2016, Peer Review 25-06-2016,

Acceptance 27-06-2016, Published 07-07-2016.

Corresponding Author:

Ravikiran Nandiraju,

26-52, Road No.-1, Haritha Homes,

Via Kanchanbag P.O., Saroornagar Mandal,

Badangpet, Hyderabad-500058,

R. R. Dist., Telangana, India.

E-mail:drnrkiran@gmail.com

DOI: 10.14260/jemds/2016/842
For a successful outcome, we need to preserve normal axial biomechanics, of knee and ankle joint, preserve the joint articulature and also preserve the near normal arc of motion of the joint. Preoperative assessment of pattern and type, assessment of grade of soft tissue trauma, availability of bone stock, imperatively decides the modality of fracture fixation, which may comprise of external devices, interlocking intramedullary nailing or osteosynthesis using plating.

Encouraging results for open reduction and internal fixation (Plate osteosynthesis) and closed manual reduction with osteosynthesis with minimal invasive percutaneous locking plates has been noted for lower third tibial fractures. Locking compression plate provides the advantage of anatomic reduction, stable fixation, preservation of blood supply, preventing joint stiffness, less soft tissue injury.

The aim of the present study was to assess the outcome of treatment of lower third tibial fracture using locking compression plate by both open and minimal invasive techniques in terms of rate of union, leg length difference and gait, return to daily routine activities, and other consequences associated with distal tibia plating and compare the results achieved by other researches and to describe any complications and evaluate the functional outcome.

\section{MATERIALS/METHODS}

This study included (40) patients with distal tibia fracture, presenting in the Department of Orthopaedics in Osmania Medical College and Osmania General Hospital. 


\section{Inclusion Criteria}

1. Age $>18$ years.

2. All closed distal $1 / 3$ tibia fractures (Intra and Extra articular) (Communicated/non-communicated).

3. Open Gustillo4 type-1.

4. Duration $<2$ weeks.

\section{Exclusion Criteria}

1. Fracture $>2$ Weeks.

2. Location infection.

3. Any pathological fractures.

4. Any associated trauma involving vital organ of body and associated comorbid conditions that hampers mobilization of affected limb.

\section{Treatment Protocol Included}

Major trauma was assessed with $1^{0}$ survey and $2^{0}$ survey as per ATLS fracture was assessed and classified according to A0/OTA classification ${ }^{5}$ later detailed his long regarding age, sex, mode of injury, time since injury, and pre-injury morbidity was taken.

$\mathrm{X}$-rays were taken is 2 planes, $\mathrm{AP}$, lateral, and mortise view including ipsilateral knee and ankle.

In open fracture, wound washing with $\mathrm{H}_{2} \mathrm{O}_{2}$ and saline was done and prophylactic antitetanus and IV antibiotics were given.

\section{PROCEDURE}

With patient positioned supine on radiolucent table under image intensifier guidance and under tourniquet control using anteromedial 6 approach to tibia and MIPO technique using smooth gentle curved $5 \mathrm{~cm}$ incision over tip of medial malleoli taking care not to cut saphenous vein.

The articular fragments were reduced anatomically percutaneously by indirect reduction using intensifier and pointed reduction forceps and help in position at times using ' $\mathrm{K}$ ' wires temporarily after creating a subcutaneous tunnel along medial aspect of tibia by blunt dissection, preselected distal tibia contoured plate was advanced through the tunnel, bridging the fracture site, plate was placed parallel to the posterior borders of distal tibia, and checked under image intensifier in both AP and lateral planes. A small incision at proximal end of plate, threaded drill sleeve in most proximal hole of plate was a good handle for correct plate positioning. The plate was then temporarily fixed with ' $K$ ' wires after confirming the axial, rotational alignment of fracture under image intensifier, distal and proximal locking screws were inserted. For safety reasons, a minimum of three screws are recommended on either side of fracture.

\section{Postoperatively}

A below knee plaster splint was usually applied with ankle in neutral position to prevent equinus deformity and leg was elevated to reduce swelling. Physiotherapy was started immediately after subsidence of postoperative acute pain.

- Patient were followed up in 6 weeks, 8 weeks, 12 weeks, and 6 months.

- $\quad$ Partial protected weight bearing started as the first sign of callus seen in follow up x-ray usually $8^{\text {th }}-10^{\text {th }}$ week.

- Full weight bearing started as union achieved in 3 of 4 cortices usually around 18-20 wks.

- $\quad$ At final follow up, patients were evaluated using AOFAS7 score for hindfoot scale (100 points).
Pain (40 points), function ( 50 points), limitation of activity, walking distance on blocks, walking surface, gait abnormality, sagittal motion, hindfoot motion, ankle hindfoot stability and alignment.

\section{RESULTS}

Endpoint of treatment of fracture was clinical and radiological union with no residual deformity and no functional disability. The study period was from June 2015 to April 2016.

The age of patient ranged from 18 to 65 , fracture being common in $4^{\text {th }}$ decade and more in males (M-80\%, F-20\%) (M32 F-8), 18-right sided and 22-left-sided fractures were noted. $60 \%$, i.e. 24 patients sustained injury following RTA, $20 \%$ (8) fall from height, $5 \%(2)$ fall of heavy object. $15 \%$ were low energy-induced fractures. 75\% (30) were closed fractures, $25 \%$ (10) being Gr-I Compound.

\section{OTA classification: ${ }^{5} \mathrm{~A} 1$ - $22 \mathrm{~B} 1-2$}

$$
\text { A2 - } 14 \text { C1-2 }
$$

- $\quad 80 \%$ (32) of cases had associated fracture of lower third of fibula.

- $\quad 30 \%$ (12) had associated other bone fractures, 12 underwent fibula fixation.

- $\quad$ All the cases were operated under spinal anaesthesia.

- Duration between injury and surgery was

$$
\begin{aligned}
& 1 \text { - } 5 \text { days (8) } \\
& 6 \text { - } 10 \text { days (20) } \\
& 15 \text { days and above (12) }
\end{aligned}
$$

\section{Duration of Fracture Union}

All the fractures united with an average of 18.7 weeks, MIPO 18.3 weeks, open reduction and internal fixation 19.2 weeks $\left(16^{\text {th }}\right.$ week - 14) $\left(18^{\text {th }}\right.$ week - 4) $\left(20^{\text {th }}\right.$ week - 14) (22nd week - 8).

\section{Function results (AOFAS) Score}

At final follow up, patient were evaluated using AOFAS score and categorised accordingly

$>85$ = Excellent, $70-80$ = good, 55-65 = fair

$<50=$ poor,

Excellent-26 (65\%)

Good-12 (30\%)

Fair-2 (5\%)

\section{Complications}

There were no cases of intraop complications.

\section{Postop Complications}

1. Superficial skin infection-4

2. Deep infection-0

3. Ankle movement restriction: Mild $<25 \%-12$

Most 25 to $75-0$

Severe $>75-0$

4. Ankle oedema-4

5. Infected union-1

6. Delayed union-1

Most of the patients were immobilised for 10-15 days. Partial weight bearing was started 4 to 11 weeks with a mean of 6 weeks. 


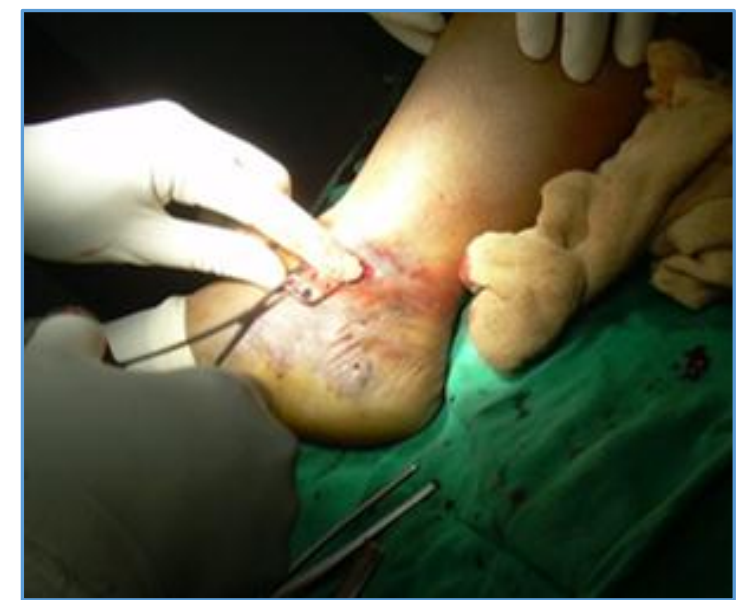

Surgical Procedure
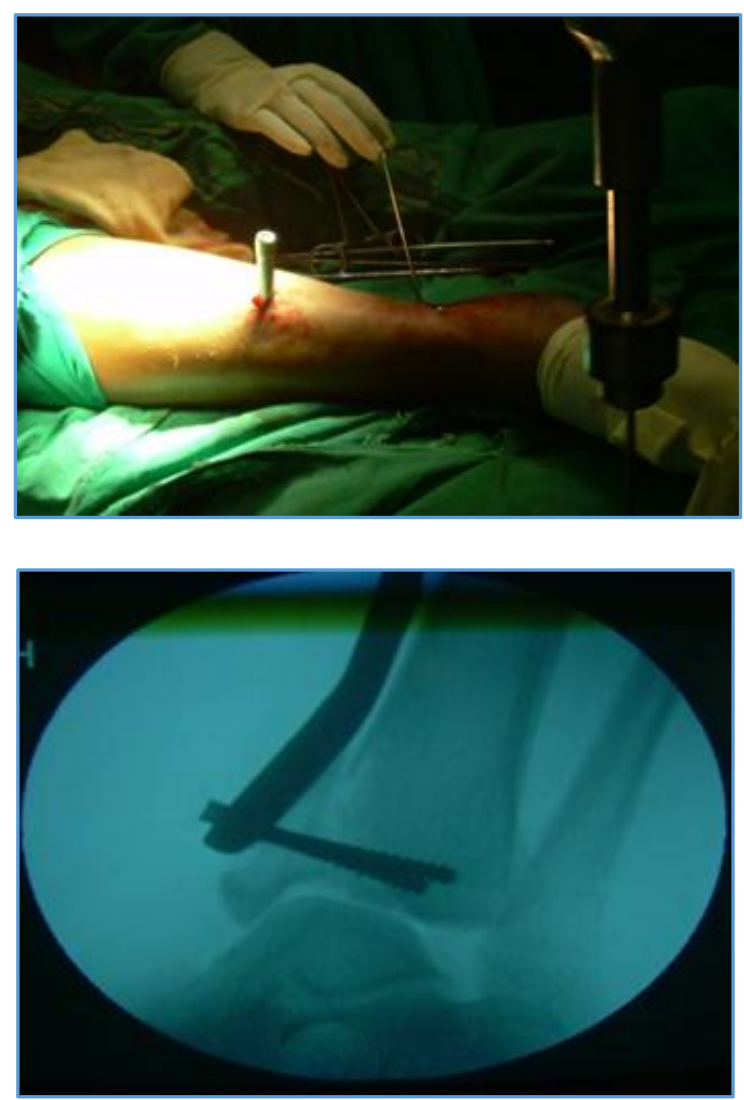

C-Aram Image Intraop

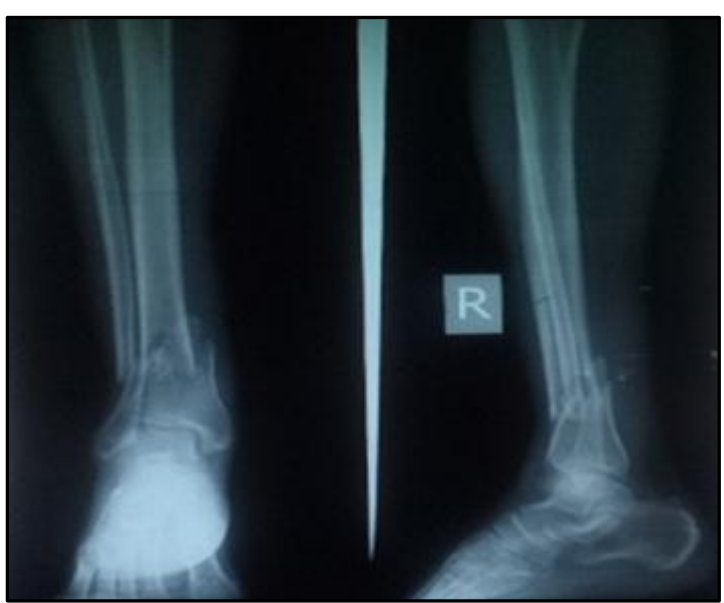

Preoperative X-Ray

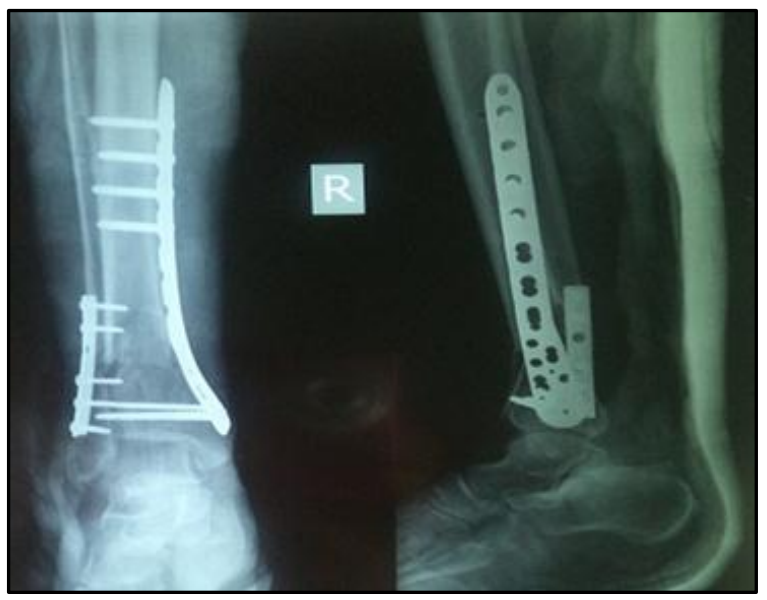

Postoperative X-Ray

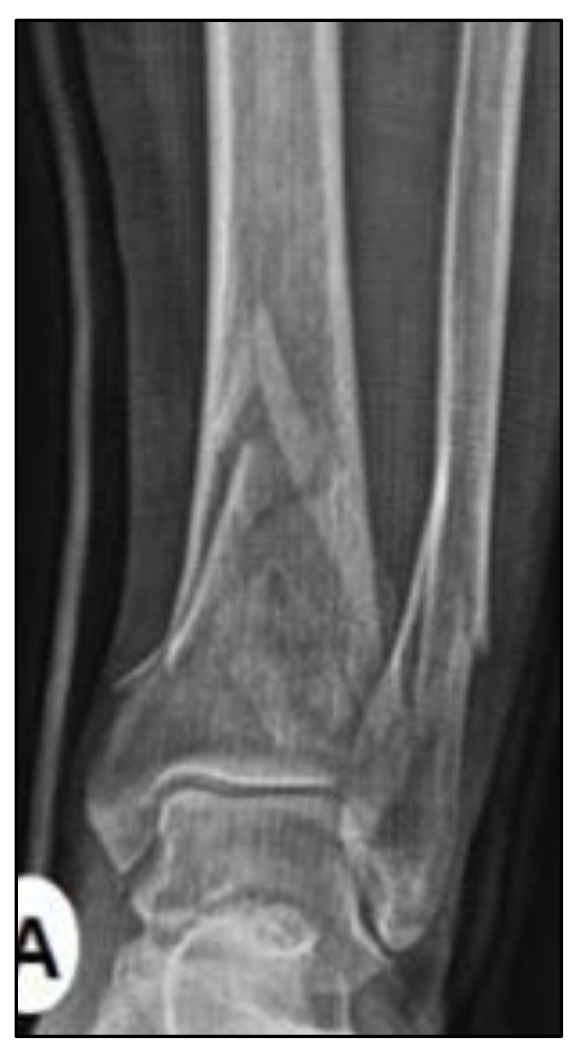

Preoperative

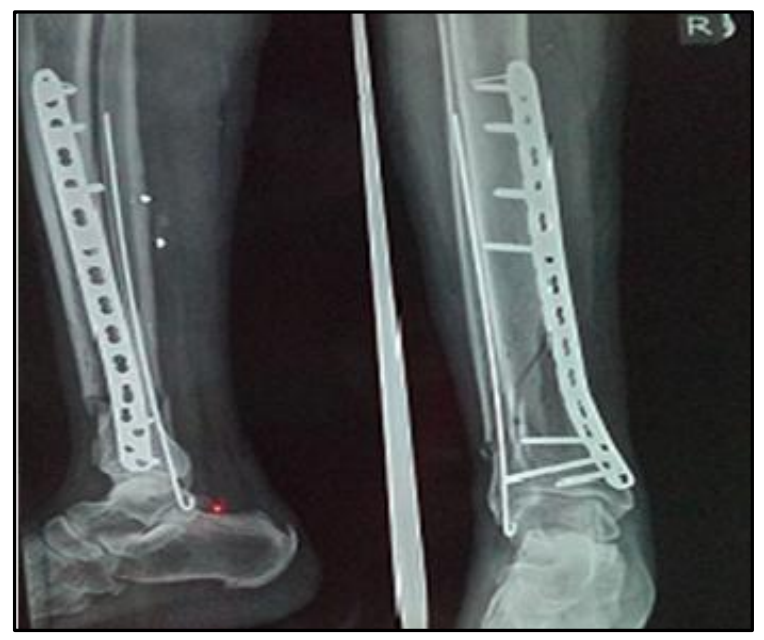




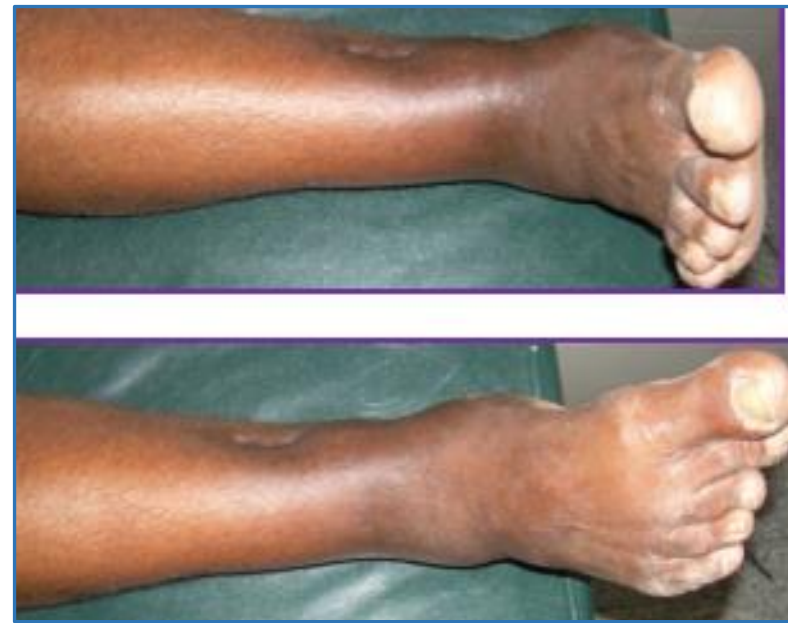

Postoperative X-Rays and Photos

\section{DISCUSSION}

Tibia is the most common fractured long bone. Most articular fractures of distal tibial weight bearing surface are the result of high energy mechanisms mostly occurring due to road traffic accidents, fall from heights, or industrial and domestic mishaps. ${ }^{8}$ Malleolar fractures are typically because of rotational mechanism and lower energy fractures whereas the primary result of axial loading forces in which talus is forced proximally into distal tibia producing the "explosion" fracture of articular surface. In this study, we have prospectively studied the outcomes of surgical treatment of these fractures using LCP. ${ }^{9}$ Fractures were classified according AO/OTA Classification and AOFAS score was to assess functional outcome. Bone union was defined as presence of bridging callous and full weight bearing without pain.

We evaluated our results and compared there with those obtained by various other studies utilizing different modalities of treatment. Our study revealed the average age of patients with such injuries to be 41.36 yrs.

\begin{tabular}{|c|c|c|c|c|c|c|c|}
\hline Study & $\begin{array}{c}\text { Minimum } \\
\text { Age }\end{array}$ & $\begin{array}{c}\text { Maximum } \\
\text { Age }\end{array}$ & $\begin{array}{c}\text { Average } \\
\text { Age }\end{array}$ & $\begin{array}{c}\text { Males } \\
\text { \% }\end{array}$ & $\begin{array}{c}\text { Females } \\
\text { \% }\end{array}$ & $\begin{array}{c}\text { High } \\
\text { Energy }\end{array}$ & $\begin{array}{c}\text { Low } \\
\text { Energy }\end{array}$ \\
\hline Cory Collinge et al10 & 17 & 62 & 43 & 77 & 23 & $100 \%$ & $0 \%$ \\
\hline $\begin{array}{c}\text { Heather A Vallier et } \\
\text { al11 }\end{array}$ & 16 & 77 & 39.1 & 69 & 31 & $51 \%$ & $49 \%$ \\
\hline Shrestha D et al 12 & 20 & 65 & 38.75 & 60 & 40 & $50 \%$ & $50 \%$ \\
\hline Present study & 18 & 65 & 41.36 & 80 & 20 & $85 \%$ & $15 \%$ \\
\hline \multicolumn{7}{|r|}{ Table 1 } \\
\hline
\end{tabular}

Male preponderance for such kind of injuries were high $80 \%$ possibly due to the fact of male dominance over the female in travelling and occupational injuries.

Present study shows $85 \%$ of fractures attributed to high energy, 15\% to low energy (Simple fall) (Sporting injuries), $25 \%$ had open $\mathrm{Gr}-1$ comp fractures, $75 \%$ closed fractures comparable to studies by Heather A Vallier et al and Hazarika et $\mathrm{al}^{13}$ who had $30 \%$ and $40 \%$ of open fractures respectively.

The average time for fracture union in various studies was 16-28 weeks, our study has an average of 18.7 weeks with MIPO procedure 18.36 weeks and ORIF 19.11 weeks comparable with other such studies using locking compression plates.

Postoperatively, 4 patients developed superficial skin infection, 12 patients developed mild ankle stiffness, 2 patients developed ankle oedema, infected union in 1 patient.

Good range of mobility of ankle joint was present in almost all patients. No cases of malunion or non-union was seen. In our study, partial weight bearing was started after a mean duration of 6 weeks (4-11 weeks) and full weight bearing initiated after conformation of callous radiologically and pain free condition at a mean of 12 weeks.

\section{CONCLUSION}

Reduction and internal fixation of distal tibial fractures using locking compression plate medially by open and MIPO technique is one of the acceptable forms of treatment for lower third tibia including the articular surface with or without communication.

We found that MIPO technique preserved soft tissue and decreased complications though indirect reduction done in this technique has a steep learning curve, good bone union, better functional outcome, and decreased complications were seen.
MIPO is a simple, rapid, and straight forward procedure, which has a reduced surgical time in both extra articular and intra articular fractures due to newer anatomically contoured LCP for the distal tibia fractures.

\section{REFERENCES}

1. Court-brown CM, Rimmer S, Prakash U, et al. The epidemiology of open long bone fractures. Injury 1998;29(7):529-34.

2. Bourne RB, Rorabeck $\mathrm{CH}$, Macnab J. Intra-articular fractures of the distal tibia: the pilon fracture. J Trauma 1983;23(7):591-6.

3. Nork SE. Distal tibia fractures. In: Stannard JP, Schmidt AH, Kregor PJ, eds. Surgical Treatment of Orthopaedic Trauma. New York: Thieme 2007:767-91.

4. Gustilo RB. The fracture classification manual. St Louis, Mosby 1991.

5. Fracture and dislocation compendium: orthopaedic trauma association committee for coding and classification. J Orthop Trauma 1996;10(Suppl 1):v-ix, 1-154.

6. Robert BW, James HD, Court-Brown, et al. Anteromedial approaches to distal tibia. $7^{\text {th }}$ ed. Rockwood 1940.

7. Glenn, Pfeffer. AOFAS SCORE, foot and ankle surgery page no 678.

8. Marsh JL, Saltzman CL. Ankle Fractures. Bucholz RW, Heckman JD, eds. Rockwood and Green's fractures in Adults. $5^{\text {th }}$ ed. Philadelphia, Lippincott, Williams and Wilkins 2001:2051.

9. Niemeyer P, Sudkamp NP. Principles and clinical application of the locking compression plat(LCP). Acta Chir Orthop Traumatol Cech 2006;73(4):221-8. 
10. Collinge C, Protzman R. Outcomes of minimally invasive plate osteosynthesis for metaphyseal distal tibia fractures. J Orthop Trauma 2010;24(1):24-9.

11. Vallier HA, Le TT, Bedi A. Radiographic and clinical comparisons of distal tibia shaft fractures (4 to $11 \mathrm{~cm}$ proximal to the plafond): plating versus intramedullary nailing. J Orthop Trauma 2008;22(5):307-11.
12. Shrestha D, Acharya BM, Shrestha PM. Minimallyinvasive plate osteosynthesis with locking compression plate for distal diametaphyseal tibia fracture. Kathmandu Univ Med J 2011;34(2):62-8.

13. Hazarika S, Chakravarthy J, Cooper J. Minimally-invasive locking plate osteosynthesis for fractures of the distal tibia-results in 20 patients. Injury 2006;37(9):877-87. 